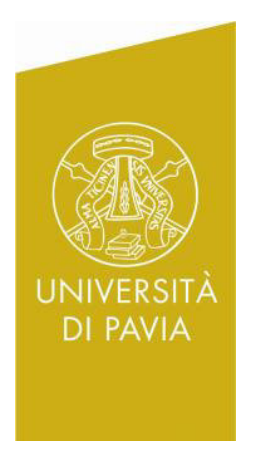

Department of Economics and Management DEM Working Paper Series

\title{
HIERARCHICAL GRAPHICAL MODELS, WITH APPLICATION TO SYSTEMIC RISK
}

\author{
Daniel Felix Ahelegbey \\ (Università di Venezia, Ca' Foscari) \\ Paolo Giudici \\ (Università di Pavia) \\ \# 63 (01-14) \\ Via San Felice, 5 \\ I-27100 Pavia \\ http://epmq.unipv.eu/site/home.html
}

January 2014 
Submitted to the Annals of Applied Statistics

\title{
HIERARCHICAL GRAPHICAL MODELS, WITH APPLICATION TO SYSTEMIC RISK
}

\author{
By Daniel Felix Ahelegbey* and Paolo Giudici ${ }^{\dagger}$ \\ University of Venice * and University of Pavia ${ }^{\dagger}$
}

Abstract

The latest financial crisis has stressed the need of understanding the world financial system as a network of interconnected institutions, where financial linkages play a fundamental role in the spread of systemic risks. In this paper we propose to enrich the topological perspective of network models with a more structured statistical framework, that of Bayesian graphical Gaussian models. From a statistical viewpoint, we propose a new class of hierarchical Bayesian graphical models, that can split correlations between institutions into country specific and idiosyncratic ones, in a way that parallels the decomposition of returns in the well-known Capital Asset Pricing Model. From a financial economics viewpoint, we suggest a way to model systemic risk that can explicitly take into account frictions between different financial markets, particularly suited to study the on-going banking union process in Europe. From a computational viewpoint, we develop a novel Markov Chain Monte Carlo algorithm based on Bayes factor thresholding.

1. Motivation. In the latest financial crisis, started in 2007 , the core capital of banks has proved to be insufficient to cover impairment losses arising from loans and security portfolios. Consequently, several banks have been strengthened their capital base or reduced their asset exposure. Other banks have been bailed out by state aids or have defaulted. To reduce the risk of similar crises in the future and to enhance the resilience of the banking sector, a new regulatory framework, the so-called Basel III package, has been proposed, implying more stringent capital requirements for financial institutions [49]. The effectiveness of the new regulatory framework to prevent banking default and financial crisis is an open problem, particularly as regulations themselves are still in progress, and may thus benefit from the results of research findings in the filed.

The study of bank failures is important for two reasons. First, an understanding of the factors related to bank failure enables regulatory authorities to supervise banks more efficiently. In other words, if supervisors can detect

Keywords and phrases: Applied Bayesian models, Graphical Gaussian Models, Systemic financial risk 
problems early enough, regulatory actions can be taken, to prevent a bank from failing and, therefore, to reduce the costs of its bail-in, faced by shareholders, bondholders and depositors; as well as those of its bail-out, faced by the governments and, therefore, by the taxpayers. Second, the failure of a bank very likely induces failures of other banks or of parts of the financial system as a whole. Understanding the determinants of a single bank failure may thus help to understand the determinants of financial systemic risks, were they due to microeconomic, idiosyncratic factors or to macroeconomic imbalances. When problems are detected, their causes can be removed or isolated, to limit "contagion effects".

The literature on predictive models for single bank failures is relatively recent: until the 1990s most authors emphasize the absence of default risk of a bank [see e.g. 28, 55], in the presence of a generalized expectation of state interventions. However, in the last years we have witnessed the emergence of financial crisis in different areas of the world, and a correlated emphasis on systemic financial risks. In addition, government themselves are less willing than before to save banks, partly for their financial shortages and partly for a growing negative sentiment from the public opinion. As a consequence of all of these aspects, the very recent years are seeing a growing body of literature on bank failures, and systemic risks originated from such them.

The studies on bank failures can be classified into three main streams: financial market models, scoring models and macroeconomic models.

Financial market models originate from the seminal paper of Merton [47], in which the market value of a bank's assets, typically modeled as a diffusion process, is insufficient to meet its liabilities. Due to its practical limitations, Merton's model has been evolved into a reduced form [see e.g. 60], leading to a widespread diffusion of the resulting model, and the related implementation in Basel II credit portfolio model. For a review of this evolution see, for example, the book by [52]. In order to implement market models, diffusion process parameters and, therefore, bank default probabilities can be obtained on the basis of share price data that can be collected almost in real time from financial markets. Market data are relatively easy to collect, are public, and are quite objective. On the other hand, they may not reflect the true fundamentals of the underlying financial institutions, and may lead to a biased estimation of the probability of failure. Indeed, the recent paper by [33] and [19] show that market models may be good in very short-term predictions, but not in medium and long-term ones, where the importance of fundamental financial data emerge.

Scoring models are based only on financial fundamentals, taken from the publicly available balance sheet information. Their diffusion followed the 
seminal paper by Altman [4], has induced the production of scoring models for banks themselves: noticeable examples are [58], [59], [54], [15]. The development of the Basel regulation (www.bis.org) and the recent financial crisis have further boosted the literature on scoring models for banking failure predictions. Recent examples include [5], [17] who use logit models; [61] who use a probit model and [37] who use a principal component factor approach. Scoring models have been extended in different ways: interesting developments include the incorporation of macroeconomic components (see e.g. [38] [45], [34] and [36]) and the explicit consideration of the credit portfolio, as in the Symbol model of [41], that allows stress tests of banking asset quality and capital, as emphasized in the recent paper by [30]. The problem with scoring models is that they are mostly based on balance sheet data, which have, differently from the market, a low frequency of update (annual or, at best, quarterly) and do depend on subjective strategic choices. They may thus be good to predict defaults (especially in the medium term) but not in the assessment of systemic risks, which occurr very dynamically and with short notice.

Our focus here will not be on the prediction of single defaults but rather, on how such prediction are correlated with each other, in a systemic perspective. The research literature on systemic risk is very recent, and follows closely the developments of the recent financial crisis. A comprehensive review is provided in [10] who also provide a historical comparison of different crisis. Specific measures of systemic risk have been proposed, in particular, by [2], [1], [9], [32], [8] and, from a different perspective, [56]. All of these approaches are built on financial market price information, on the basis of which they lead to the estimation of appropriate quantiles of the estimated loss probability distribution of a financial institution, conditional on a crash event on the financial market. These literature developments have lead and are still contributing to the identification of the Systemically Important Financial Institutions (SIFIs), at the global and regional level. They however do not address the issue of how risks are transmitted between different insitutions.

Systemic risk can indeed also be defined as the risk that the failure of one significant financial institution can cause or significantly contribute to the failure of other significant financial institutions, as a result of their linkages to each other [see e.g. 8]. Trying to address this aspect of systemic risks, researchers have recently proposed network models, that can help model the systemic risk in financial systems which display complex degrees of connectedness. In particular, [8] propose several econometric measures of connectedness based on principal component analysis and Granger-causality networks. 
They find that hedge funds, banks and insurance companies have become highly interrelated over the past decade, likely increasing the level of systemic risk through a complex and time-varying network of relationships. [13] and [6] follow similar approaches.

The adoption of a robust financial network approach in the above context is recommended not only because of its proper emphasis on financial interdependencies, but also for its possibility to describe how the structure of these interdependencies evolves in time. Were this be achieved, we would be able to address systemic financial risks in two directions: on one hand, to understand the role that a network structure plays in the spread of financial shocks; on the other hand, to understand the impact of simulated stress events on a network of interdependencies (see, for example, $[48,21,23,12,46,16,51])$. Simulated networks, as those described in the previous paper, can help studying the impact of crisis scenarios on the system, in a stress-testing framework. However, they typically assume a fixed network structure which may not be the one supported by the data.

To learn financial networks from the data we propose empowering network models with multivariate graphical models. Graphical models embed the idea that interactions among random variables in a system can be represented in the form of graphs, whose nodes represents the variables and whose edges shows their interactions. For an introduction to graphical models see, for example, [50, 40, 64, 63, 18, 39].

Graphical models can be employed to accurately estimate the adjacency matrix, aimed at measuring interconnectedness between different financial institutions and, in particular, to assess central ones that may be the most contaged or the strongest source of contagion [as in 8]. Network models use the correlation matrix estimated from the data to derive the adjacency matrix. Although useful, this approach takes into account only the marginal (indirect) effect of a variable on another, without looking at the (direct) effect of other variables. In our context, it does not distinguish between the direct and the indirect effect of a country on other ones. Graphical models, instead, focus on the partial correlation matrix, that is obtained by measuring only the direct correlation between two variables. A partial correlation coefficient can express the change in the expected value of a dependent variable, caused by a unitary change of the independent variables, when the remaining variables are held constant. In so doing, the effect of a bank on another is split into a direct effect (estimated by the partial correlation) and an indirect effect (what is left in the marginal correlation). Here we follow this approach and derive the adjacency matrix, the main input of a financial network model, not from the correlation matrix but, 
rather, from the partial correlation matrix obtained from the application of graphical models to the available data.

To achieve this aim we consider multivariate Gaussian graphical models, defined in terms of Markov properties, that is, conditional independencies associated with the underlying graph [39, 64]. While traditional network models assume fixed graphical structures (such as fully connected graphs), the structure of a graphical model is typically random, and can be learned from the data, as a good fitting structure. Such a model selection can be performed by testing, in a stepwise procedure, the statistical significance of conditional independencies, which are equivalent to specified zeroes among certain partial correlation coefficients which, in turn, are equivalent to missing edges in the network representation.

The use of graphical models can thus help to have a deeper understanding of the relationships between variables, by distinguishing direct from indirect relationships. From their appearance in the 90's, several methodological advances have been made for graphical models. Less so in terms of applications, especially in financial economics. In our opinion, this requires to solve two main problems.

First, the assumption of a random graph may be an important added value in situations where little a priori knowledge is present, as is the case for systemic risk. In addition, results should not be conditioned on single models, but, rather, should be model averaged, to avoid suboptimal inferences.

Second, graphical models do not allow to decompose asset return correlations into market specific and idiosyncratic effects, as in the classical CAPM models [57]. This assumption seems to be restrictive in finance.

The first problem can be solved with the use of more advanced, Bayesian, graphical models, as shown in [43], [25] and, more recently, [3]. In particular, [43] and [25] propose a Bayesian model able to consider all possible graphical structures, choose the best fitting ones and, if necessary, average inferential results over the set of all models.

The methodological contribution of this paper can solve the second problem as well. We propose Bayesian hierarchical graphical models, that allow correlations to be decomposed, as in a CAPM-like model, into a country (market) effect plus a bank-specific (idiosyncratic) effect.

On the other hand, the applied contribution of this paper is in the understanding of whether and how a distress probability is transmitted between different banks, that belong to different countries, with different regulatory systems. The world financial market is not perfect: many frictions exists between different countries, mainly due to different regulations, given the fundamental relevance of banks for the economies to which they belong. 
A very interesting case study, in this respect, is the Eurozone, where the European Central Bank (ECB) has recently taken over the supervision of the largest banks (with total assets greater than 30bn euro) in each of the member states. Thus, eventually, the euro banking market will evolve into a single market but, at the time being, it is still fragmented. It thus becomes timely and rather interesting to study the degree of convergence towards a European banking union, looking at the comovements between stock returns of the banks in the area, that may give important insights.

Finally, we remark that the paper also contributes to computational statistics as, in order to apply the proposed hierarchical model to the large $p /$ small $n$ database at hand, a novel Markov Chain Monte Carlo algortihm, based on Bayes factor thresholding, has been developed and implemented in a Matlab routine, available upon request.

The paper is organized as follows. In Section 2, we introduce Bayesian graphical models, and show their theoretical implications: in particular, we show how a hierarchical approach can decompose the variance-covariance matrix of the model into a variance-covariance matrix between countries and, conditionally on it, on a bvariance-covariance matrix between banks. In Section 3 we introduce a simulated data application that is helpful for the set-up of our computational methodology. Section 4 describes the empirical results obtained with the application of the Bayesian hierarchical graphical models to the data. Finally, section 5 contains some concluding remarks and future research directions.

2. Methodology. In this section we review the basics of Bayesian graphical models and present a detailed description of the methodology proposed in the paper.

2.1. Review of Bayesian Graphical models. Let $X=\left(X_{1}, \ldots, X_{n}\right) \in R^{n}$ be a random vector distributed according to a multivariate normal distribution $\mathcal{N}_{n}(\mu, \Sigma)$. In this paper, without loss of generality, we will assume that the data are generated by a stationary process, and, therefore, $\mu=0$. In addition, we will assume throughout that the covariance matrix $\Sigma$ is non singular. Let $G=(V, E)$ be an undirected graph, with vertex set $V=\{1, \ldots, n\}$, and edge set $E=V \times V$, a binary matrix, with elements $e_{i j}$, that describes whether pairs of vertices are (symmetrically) linked between each other $\left(e_{i j}=1\right)$, or not $\left(e_{i j}=0\right)$. If the vertices $V$ of this graph are put in correspondence with the random variables $X_{1}, \ldots, X_{n}$, the edge set $E$ induces conditional independence on $X$ via the so-called Markov properties [see e.g. 39]. More precisely, the pairwise Markov property determined by $G$ states 
that, for all $1 \leq i<j \leq n$,

$$
e_{i j}=0 \Longleftrightarrow X_{i} \perp X_{j} \mid X_{V \backslash\{i, j\}} ;
$$

that is, the absence of an edge between vertices $i$ and $j$ is equivalent to independence between the random variables $X_{i}$ and $X_{j}$, conditionally on all other variables $X_{V \backslash\{i, j\}}$.

Statistical inference for graphical models can be of two kinds: quantitative learning, which means that, given a graphical structure, with associated Markov properties, data is employed to estimate the unknown parameters of the model; and structural learning, which means that the graphical structure itself is estimated on the basis of the data. Here we focus on the latter.

The structural learning problem has been described to be NP-hard (nondeterministic polynomial-time hard) by [14]. This is because the cardinality of the space of possible structures grows super-exponentially with the number of nodes. However, graphical model uncertainty can be taken into account, along with parameter uncertainty, within a Bayesian approach, whose main practical advantage is that inferences on quantities of interest can be averaged over different models, each of which has a weight that corresponds to its Bayesian posterior probability. See, for example, [44], [25] and [24].

To achieve this aim, the first task is to recall the expression of the marginal likelihood of a graphical Gaussian model, and specify prior distributions over the parameter $\Sigma$ as well as on the graphical structures $G$.

For a given graph $G$, let $\pi^{i}(G)$ be the neighbors of a variable $X^{i}, i=$ $1, \ldots, n$ : the set of all vertices that are connected to $i$ or, equivalently, the set of all random variables on which $X^{i}$ is conditionally dependent. Statistical inferences can be based on the likelihood of the observed data. Assuming that the observed data can be arranged in a matrix $\mathcal{X}$, with $n$ rows that are independent and identically distributed multivariate time series of dimension $T$, each following a multivariate normal distribution $\mathcal{N}_{n}(0, \Sigma)$, the likelihood of the unknown parameters $\Sigma, G$ is equal to:

$$
P(\mathcal{X} \mid \Sigma, G)=\prod_{t=1}^{T} \prod_{i=1}^{n} P\left(X_{t}^{i} \mid \pi^{i}(G), \Sigma\right)
$$

As expected, the likelihood depends on the parameters $\Sigma$ and $G$. According to the conventional Bayesian graphical model averaging paradigm [see e.g. 43], we assume that both $\Sigma$ and $G$ are random, and that a joint prior distribution over $(\Sigma, G)$ can be expressed by a discrete probability distribution over all graph structures $G$ and, conditionally on each possible graph, by a continuous distribution over the set of parameters $\Sigma$ :

$$
P(G, \Sigma)=P(G) P(\Sigma \mid G)
$$


For $P(G)$ we assume a uniform prior over all possible graphical structures while for the prior on the parameters we assume a conjugate inverse-Wishart prior. More formally, based on the assumption that we have available a random sample of size $T$ from a multivariate normal distribution $\mathcal{N}_{n}(0, \Sigma)$, we assume that $P(\Sigma)$ is an inverse-Wishart distribution with $\alpha>n$ degrees of freedom and a scale matrix $\underline{\Sigma}$.

According to the Bayesian prior-to-posterior paradigm [see 7] it can be shown that, under the previous assumptions, the posterior distribution of the precision matrix $\Sigma, P(\Sigma \mid \mathcal{X})$ is an inverse-Wishart distribution with $\alpha+T$ degrees of freedom and a scale matrix given as follows:

$$
\bar{\Sigma}=\frac{1}{\alpha+T}(\alpha \underline{\Sigma}+T \hat{\Sigma})
$$

where $\hat{\Sigma}$ is the sample variance-covariance matrix. Note that the proposed prior distributions can also be used to integrate the likelihood with respect to the unknown random parameters, obtaining the so-called marginal likelihood of a graph, which will be the main metric for model selection. This follows from

$$
P(\mathcal{X} \mid G)=P(\mathcal{X} \mid \Sigma, G) P(\Sigma)
$$

It can be shown that such marginal likelihood is equal to:

$$
P(\mathcal{X} \mid G)=(\pi)^{-\frac{n T}{2}} \prod_{i=1}^{n} \frac{\Gamma\left(\frac{\alpha+T+1-i}{2}\right)}{\Gamma\left(\frac{\alpha+1-i}{2}\right)} \cdot|\underline{\Sigma}|^{\frac{\alpha}{2}}|\bar{\Sigma}|^{-\frac{\alpha+T}{2}}
$$

where $\Gamma(\cdot)$ denotes the gamma function, and $|\underline{\Sigma}|$ and $|\bar{\Sigma}|$ are the determinants of the matrices $\underline{\Sigma}$ and $\bar{\Sigma}$. The metric expressed by the above marginal likelihood is the basic ingredient for graphical Gaussian model selection and averaging, as will now be shown.

According to the conventional Bayesian paradigm, being the model space discrete, the graphical model chosen by structural learning will then be that with the highest a posteriori probability. By Bayes rule, the posterior probability of a graph is given by:

$$
P(G \mid \mathcal{X}) \propto P(\mathcal{X} \mid G) P(G)
$$

and, therefore, since we assumed a uniform prior over the graph structures, maximizing the posterior probability is equivalent to maximizing the marginal likelihood metric. For graphical model selection purposes we shall thus search in the space of all possible graphs for the structure such that

$$
G^{*}=\arg \max _{G} P(G \mid \mathcal{X}) \propto P(\mathcal{X} \mid G) .
$$


Notice however that the Bayesian paradigm does not force conditioning inferences on the (best) model chosen. The assumption of $G$ being random, with a prior distribution on it, allows any inference on quantitative parameters to be model averaged with respect to all possible graphical structures, with weights that correspond to the posterior probabilities of each graph. This because, by Bayes' theorem:

$$
P(\Sigma \mid \mathcal{X})=P(\Sigma \mid \mathcal{X}, G) P(G \mid \mathcal{X})
$$

The above allows to overcome the main drawback of non-Bayesian graphical models, namely, the fact that, once a model is chosen, all inferences will be conditional on that model, even if it has a little support from the data (although maximal). However, in real situations, the number of possible graphical structures may be very large and we may need to restrict the number of models to be averaged. This can be done efficiently, for example, following a simulation-based procedure for model search, such as Markov Chain Monte Carlo (MCMC) sampling, described in [43]. One of the standard MCMC methods is the Metropolis-Hastings (MH) algorithm, which is based on an acceptance-rejection scheme. In our context, given an initial graph, the algorithm samples a new graph using a proposal distribution. The newly sampled graph is then compared with the old graph, with a decision rule to either reject or accept the proposed sample. More precisely, following [25], the algorithm randomly selects a node from the current graph $\left(G_{\text {old }}\right)$ and proposes an action to either add or delete a single edge to produce a new graph $\left(G_{\text {new }}\right)$. The proposed graph $G_{\text {new }}$ is either accepted, becoming $\left(G_{\text {old }}\right)$ in the next step, or rejected in which case the previous graph is maintained as $G_{\text {old }}$. The decision to accept or reject a proposed graph depends on an acceptance probability.

2.2. Hierarchical graphical models. One of the appealing features of graphical models for multivariate time series analysis is to represent graphically the logical implications as well as the conditional independence relationships among the variables. In high dimensional settings, it is extremely hard to extract meaningful information from the complex interaction among the variables. In addition, learning such complex interactions is computationally intensive when using standard structure learning schemes. There is a high chance that the learning algorithm gets trapped, spending much time to learn local optimum structures which might not be representative A possible solution to the trap problem is to add more structure to the graphical model. For example, in the Bayesian setting, the prior distribution over the graph space can be enriched and used to penalise complex strcutures. Another approach, particularly suited for the applied problem considered in 
this paper, is to employ hierarchical graphical models: this will allow most of structural learning to be localised to groups of variables which however are not independent and, thus, can borrow inferential strength from each other.

Several researchers have discussed and applied hierarchies in graphical models [see e.g. 31, 29, 65]. The approach proposed in this paper is in the spirit of $[26,27]$ but from a Bayesian perspective.

Suppose we have a large dataset of $n$ random variables, $X=\left(X_{1}, \ldots, X_{n}\right)$, that can be grouped into $k$ categories, $\left(Z_{1}, \ldots, Z_{k}\right)$, such that the $k$ th category contains $n k$ variables $Z_{k}=\left(Y_{1}, \ldots, Y_{n k}\right)$. Without loss of generality, we assume that each variable in $X$ belongs to exactly one of the categories, i.e $\sum_{i=1}^{k} n_{i}=n$, and that the observations in the same category are centered along each variable. To exemplify, the random variables in $X$ can be banks that can be grouped into $k$ different countries (represented as $Z$ ) with each country consisting of a number of banks (represented as $Y$ ), so that $X=(Y, Z)$.

In this context, we consider $Z$ as a compressed representation of the banking system in different countries. Based on the classification, we build a twolevel hierarchical model composed of: a country specific component, that explains relationships between banking systems of different countries, and an idiosyncratic component that models relationships between banks in the same country. More formally

$$
P(X)=P(Y, Z)=P(Z) P(Y \mid Z)
$$

To achieve this aim, we introduce a one-way decomposition of the covariance between any two banks, $X_{i}, X_{j} \in X$, that belong, respectively, to countries $Z_{a}$ and $Z_{b}$. Let $G_{z}$ be a $k \times k, 0 \backslash 1$ matrix, representing the structure of between country relationships. In our context, all random variables are continuous and it is assumed that $X \sim \mathcal{N}_{n}(0, \Sigma), Z \sim \mathcal{N}_{k}(0, \Phi)$ and $Y \sim \mathcal{N}_{n}(0, \Psi)$. We assume that:

$$
\begin{aligned}
\sigma_{i, j} & =g_{a, b}^{z} \circ\left(\phi_{a, b} \circ \psi_{i, j}\right)+\left(1-g_{a, b}^{z}\right) \circ \psi_{i, j}, \quad X_{i} \in Z_{a}, X_{j} \in Z_{b} \\
\sigma_{i, j} & =\left(\phi_{a, a} \circ \psi_{i, j}\right), \quad X_{i}, X_{j} \in Z_{a}, X_{i} \neq X_{j}
\end{aligned}
$$

where (o) is the Hadamard product, $g_{a, b}^{z}=G_{z}(a, b)$ captures the link between country $Z_{a}$ and $Z_{b}, \phi_{a, b}$ is the covariance between $Z_{a}$ and $Z_{b}$, and $\psi_{i, j}$ is the covariance between banks $Y_{i}$ and $Y_{j}$. This decomposition treats $\phi_{a, b}$ as a common factor controlling any linkage between two banks $Y_{i}$ and $Y_{j}$ from different countries. On the other hand, $\psi_{i, j}$ measures the covariance between banks $Y_{i}$ and $Y_{j}$, independent of a country specific effect. 
A nice aspect of the above model is that it can be further decomposed, to accommodate for further grouping effects. For instance, in our specific application, the term $\phi_{a, b}$ may be further be decomposed into a macroeconomic country effect plus a banking sector specific ones, calculating the difference between macroeconomic log returns (e.g. of the Gross Domestic Product of a country) and capitalization weighted log returns of the banking sector of a country. In addition, the term $\psi_{y_{i}, y_{j}}$ can also be similarly decomposed in groups, according to bank-specific balance sheet variables (such as asset size, leverage, etc.).

2.3. Efficient Structural Inference Scheme. We now focus on sampling the multivariate instantaneous (MIN) relationships among random variables by allowing for simultaneous interactions. We will do so by extending the work by [3]. In large dimensional settings, a common drawback of the classical Metropolis-Hastings sampling scheme is the likelihood of spending much time to learn local optimum structures which might not be representative of the global optimum structure. Secondly, sampling structures with simultaneous interactions (undirected links) leads to difficulties in diagnosing convergence of the chain. According to [43], irreducibility is guaranteed on condition that the structures satisfy acyclic constraints. This makes the standard scheme not feasible in sampling undirected structures. In this paper, we propose a Markov chain Monte Carlo scheme that employs a Bayes factor thresholding.

A sketch of the idea is as follows: We initialize the algorithm by assuming a fully connected structure $\left(G_{\text {old }}\right)$. At each iteration, we delete the edge between two variables $X_{i}$ and $X_{j}$ to produce a new structure $\left(G_{n e w}\right)$. We then compute the posterior of the two structures and compute the Bayes factor. By assuming a uniform graph prior, it can be shown that the log Bayes factor is given by:

$$
\log (B F)=\log \left(P\left(\mathcal{X} \mid G_{\text {new }}\right)\right)-\log \left(P\left(\mathcal{X} \mid G_{\text {old }}\right)\right)
$$

If $\log (B F)>\tau$, where $\tau \geq 0$, then the model of the new structure is much preferred which means that the edge between $X_{i}$ and $X_{j}$ must be deleted. However, if $\log (B F) \leq \tau$, then the edge between $X_{i}$ and $X_{j}$ can be retained. Thus the mechanism automatically accepts edges between variables leading to improvements in structural learning.

To sample our two-level hierarchical model, we marginalize out analytically the parameters of the structural model to obtain an efficient Gibbs sampling algorithm [e.g., see 11]. That is, we sample the parameters and the relationships in blocks [e.g., see 53]. Let $G_{z}$ and $G_{y}$ be the structure of 
the between country and between bank relationships. Thus, our approach involves sampling from the posterior distribution of the between country structural relationships $\left(G_{z}\right)$ given $\Psi$, then updating $\Psi$ given $\left(G_{z}\right)$. The next step involves sampling from the posterior distribution of the between banks structural relationships $\left(G_{y}\right)$ given $\Psi, \Phi$ and $G_{z}$. Let $\mathcal{X}=(\mathcal{Z}, \mathcal{Y})$ where $\mathcal{X}$ is the observed dataset of the variables arranged into $\mathcal{Z}$ and $\mathcal{Y}$ representing the country specific and bank specific dataset respectively. The resulting collapsed Gibbs sampler [42] consists of the following steps:

1. Sample between country structural relationships: $\left(G_{z} \mid \mathcal{Z}\right)$,

2. Update between country parameters: $\left(\Phi \mid \mathcal{Z}, G_{z}\right)$,

3. Sample between banks structural relationships: $\left(G_{y} \mid \mathcal{Y}, \mathcal{Z}, \Phi, G_{z}\right)$,

4. Update between banks parameters: $\left(\Psi \mid \mathcal{Y}, \mathcal{Z}, \Phi, G_{z}, G_{y}\right)$,

Following the idea by [62], we implement the algorithm such that steps 1 and 2 can be combined and step 3 and 4 as well. A pseudo presentation of the algorithm is as follows:

- Initialize $\underline{\Sigma}$ and Compute $\bar{\Sigma}$

- Initialize $G$ as fully connected

- For $t=1$ : Total iterations

- Let $G_{t}=G$

- For each edge $e_{i j} \in G_{t}$, let $G^{n}=G_{t} \backslash\left\{e_{i j}\right\}$

- Compute $\log$ Bayes factor, $\log (B F)=\log \left(P\left(\mathcal{X} \mid G^{n}\right)\right)-\log \left(P\left(\mathcal{X} \mid G_{t}\right)\right)$

* If $\log (B F)>\tau$, set $e_{i j}=0$ and sample $\underline{\sigma_{i i}}$

* Else, set $e_{i j}=1$ and sample $\underline{\sigma_{i i}}$ and $\underline{\sigma_{i j}}$

- Update $\bar{\Sigma}$

2.4. Centrality Measures. Let $A$ be $n \times n, 0 \backslash 1$ matrix, which we will call the adjacency matrix. Network statistics can be derived using $A$ : in particular, meaningful summary measures can be obtained using an appropriate singular value decomposition of such matrix. The simplest measure of node centrality is the degree which measures the number of connection of a given node in a network. In the framwork of undirected network, the degree $\left(d_{i}\right)$ of node $i$ is simply:

$$
d_{i}=\sum_{j=1}^{n} a_{i, j}
$$

where $j$ represents all other nodes, $n$ is the total number of nodes, and $a_{i j}$ is the $(i, j)$ element of the adjacency matrix of the network, which is defined as 1 if node $i$ is connected to node $j$, and 0 otherwise. 
The centrality measure that has been proposed in financial network modeling to explain the capacity of an agent to cause systemic risk, that is, a large contagion loss on other agents, is the eigenvector centrality [see e.g. $20,8]$. The eigenvector centrality measure is a measure of the importance of a node in a network. It assigns relative scores to all nodes in the network, based on the principle that connections to few high scoring nodes contribute more to the score of the node in question than equal connections to low scoring nodes.

More formally, for the $i$-th node, the centrality score is proportional to the sum of the scores of all nodes which are connected to it, as in the following equation:

$$
x_{i}=\frac{1}{\lambda} \sum_{j=1}^{n} a_{i, j} x_{j},
$$

where $x_{j}$ is the score of a node $j, a_{i, j}$ is the $(i, j)$ element of the adjacency matrix of the network, $\lambda$ is a constant and $n$ is the number of nodes of the network. The previous equation can be rewritten for all nodes, more compactly, as:

$$
A x=\lambda x,
$$

where $A$ is the adjacency matrix, $\lambda$ is the eigenvalue of the matrix $A$, with associated eigenvector $x$, an $n$-vector of scores (one for each node).

Note that, in general, there will be many different eigenvalues $\lambda$ for which a solution to the previous equation exists. However, the additional requirement that all the elements of the eigenvector be positive (a natural request in our context) implies (by the Perron-Frobenius theorem) that only the eigenvector corresponding to the largest eigenvalue provides the desired centrality measures. Therefore, once an estimate of $A$ is provided, network centrality scores can be obtained from the previous equation, as elements of the eigenvector associated to the largest eigenvalue.

In our two-level hierarchical model, it follows that the centrality measure decomposes into a country specific component, and a between banks component.

3. Simulation. In this Section we illustrate and motivate the choice of our computational algorithm, on the 6-node simulation experiment of [62]. The experiment considers a model of $n=6$ variables, with $T=18$ observations, and an estimated sum of squares $S=T \hat{\Sigma}=T A^{-1}$, where the 
upper triangular matrix of $A$ is defined as:

$$
A=\left(\begin{array}{cccccc}
1 & 0.5 & 0 & 0 & 0 & 0.4 \\
& 1 & 0.5 & 0 & 0 & 0 \\
& & 1 & 0.5 & 0 & 0 \\
& & & 1 & 0.5 & 0 \\
& & & & 1 & 0.5 \\
& & & & & 1
\end{array}\right)
$$

Using our proposed algorithm, we run 2000 Gibbs iterations with 200 burn-in ones and considered three thresholds $\tau=0,1,2$. The result of the posterior probabilities of edge presence in the graph are:

$$
\begin{aligned}
\left(\hat{p}_{i j} \mid \tau=0\right) & =\left(\begin{array}{cccccc}
1 & 0.94 & 0.02 & 0.01 & 0.02 & 0.83 \\
& 1 & 0.94 & 0.02 & 0.01 & 0.02 \\
& & 1 & 0.93 & 0.02 & 0.01 \\
& & & 1 & 0.93 & 0.01 \\
& & & & 1 & 0.94 \\
& & & & & 1
\end{array}\right) \\
\left(\hat{p}_{i j} \mid \tau=1\right) & =\left(\begin{array}{cccccc}
1 & 0.96 & 0.05 & 0.03 & 0.04 & 0.92 \\
& 1 & 0.96 & 0.04 & 0.02 & 0.04 \\
& & 1 & 0.96 & 0.04 & 0.03 \\
& & & 1 & 0.96 & 0.04 \\
& & & & 1 & 0.96 \\
& & & & & 1
\end{array}\right) \\
\left(\hat{p}_{i j} \mid \tau=2\right) & =\left(\begin{array}{cccccc}
1 & 0.95 & 0.76 & 0.76 & 0.76 & 0.92 \\
& 1 & 0.95 & 0.77 & 0.76 & 0.76 \\
& & 1 & 0.94 & 0.78 & 0.77 \\
& & & 1 & 0.95 & 0.77 \\
& & & & 1 & 0.96 \\
& & & & & 1
\end{array}\right)
\end{aligned}
$$

Following the idea of testing significance of regression coefficients, we apply a test for significance of an edge between two variables. We test if the posterior edge probability is greater than 0.5 under a $95 \%$ credibility interval. If this is true, then the edge is statistically significant, otherwise there is no link between the variables.

By comparing the results with the data generating process, we observe that fixing a threshold $\tau=0$ or 1 produces an accurate description of the data generating process. According to the scale provided by [35], using $\tau=0$ leads to accepting edges that are not worth more than a bare mention. However, fixing $\tau=1$ produces strong evidence against the null network. When $\tau=2$, we observe from the results that the algorithm overestimates the number of links in the network therefore yielding an unsatisfactory representation of the links. Based on these results, we consider $\tau=1$ as a robust logarithm Bayes factor threshold for our empirical application, that will be presented in the next Section.

4. Application. In this section we apply our proposed model to the estimation of the systemic credit risk of the largest listed banks of the Eu- 
rozone. We consider the Eurozone because of the changes in progress in this area, where the European central bank has started the take over of the supervision of the largest banks on November 1st, 2013. It is a gradual process, that aims at replacing the previous fragmented supervision and regulation (between 17 member states) into a unified one, with common rules and practices. It thus seems timely and important to focus the analysis on the banks that belong to this area, with the aim of contributing to identifying the most contagious institutions, at the super-national level.

Data. In this research we consider only large banks, whose total assets are greater than $30 b$ euros, and that are included in the ECB comprehensive assessment review. As we aim for an approach that integrates market information with bank-specific data, we consider only publicly listed banks, for which market data is available. Finally, in the case of a banking group with more entities that satisfy the above criteria, we consider only the controlling entity. The complete list of the 45 considered financial institutions is in Table 1, with the corresponding ticker code acronyms. To complete the information, Table 1 contains, besides bank names and their codes, their prevalent country, whether they are Systematically Important Financial Institutions (SIFI) either at the Global or at the Domestic level, their Total Assets from the last available balance sheet (in thousands of euro), the Year Over Year variation of their equity returns (in percentage points), and the corresponding standard deviation of the returns, also in percentage points.

From Table 1, note that 12 of the 17 eurozone countries have at least one bank with total assets greater than $30 b n$ euro. The five missing countries are Estonia, Luxembourg, Malta, Slovakia and Slovenia.

Apart from the missing (small) countries, Table 1 underlines a remarkable difference in the banking structure of the different countries, that is to be remembered when interpreting the obtained results. Some countries have a large number of banks in the sample: Italy, the third populated country, has 12 , Spain, the fourth populated country, has 7. Others have instead a limited number of banks: Germany, the most populated country, has only 5, and so does France, the second populated country. Note that Greece, a small country, with the most troubled eurozone economy, has 4. For comparison purposes, the ECB assessment sample (that includes unlisted banks) contains a total of 130 banks in the Eurozone, among which 24 German banks, 13 French, 15 Italian, 16 Spanish and 4 Greek ones. Looking at country representation note that our sample of banks, which does represent about a third of all banks in the ECB list, is overrepresented in terms of Greece banks (it contains them all) and Italian banks (has about $80 \%$ of them), 
TABLE 1

Banks Description - Listed and Supervised by the European Central Bank

\begin{tabular}{|c|c|c|c|c|c|c|}
\hline Bank Name & Code & Country & T.Assets & SIFI & YOY & Stdev \\
\hline Deutsche Bank & DBK & Germany & 2012329 & $\mathrm{G}$ & 3.96 & 4.00 \\
\hline BNP Paribas & BNP & France & 1907290 & $\mathrm{G}$ & 26.94 & 3.59 \\
\hline Credit Agricole & ACA & France & 1842361 & $\mathrm{G}$ & 37.42 & 4.39 \\
\hline Banco Santander & SAN & Spain & 1269628 & $\mathrm{G}$ & 10.90 & 3.60 \\
\hline Societe Generale & GLE & France & 1250696 & $\mathrm{G}$ & 44.17 & 4.96 \\
\hline ING Groep & INGA & Netherland & 1168632 & G & 24.86 & 4.08 \\
\hline UniCredit & UCG & Italy & 926827 & $\mathrm{G}$ & 41.21 & 4.99 \\
\hline Intesa Sanpaolo & ISP & Italy & 673472 & $\mathrm{D}$ & 30.72 & 4.45 \\
\hline Banco Bilbao Vizcaya Argentaria & BBVA & Spain & 637785 & $\mathrm{G}$ & 32.08 & 3.82 \\
\hline Commerzbank & CBK & Germany & 635878 & $\mathrm{G}$ & -48.65 & 7.28 \\
\hline Natixis-BPCE Group & $\mathrm{KN}$ & France & 528370 & $\mathrm{G}$ & 37.39 & 4.74 \\
\hline Dexia & DEXB & Belgium & 357210 & $\mathrm{G}$ & -133.50 & 22.46 \\
\hline Caixabank & CABK & Spain & 348294 & - & 25.86 & 5.08 \\
\hline Bankia & BKIA & Spain & 282310 & - & -469.33 & 32.13 \\
\hline KBC Group & $\mathrm{KBC}$ & Belgium & 256886 & $\mathrm{D}$ & 72.92 & 4.16 \\
\hline CIC Credit Mutuel Group & $\mathrm{CC}$ & France & 235732 & - & 33.69 & 2.02 \\
\hline Banca Monte dei Paschi di Siena & BMPS & Italy & 218882 & - & 2.39 & 6.29 \\
\hline Erste Group Bank & EBS & Austria & 213824 & $\mathrm{D}$ & 24.34 & 4.52 \\
\hline Banco de Sabadell & SAB & Spain & 161547 & - & -3.57 & 6.21 \\
\hline Banco Popular Espanol & POP & Spain & 157618 & - & -44.69 & 12.19 \\
\hline Bank of Ireland & BIR & Ireland & 148146 & $\mathrm{D}$ & 91.20 & 5.80 \\
\hline Raiffeisen Bank International & RBI & Austria & 136116 & $\mathrm{D}$ & -25.59 & 3.91 \\
\hline Unione di Banche Italiane & UBI & Italy & 132433 & - & 38.72 & 5.30 \\
\hline Banco Popolare & $\mathrm{BP}$ & Italy & 131921 & - & 7.77 & 6.13 \\
\hline Allied Irish Banks & AIB & Ireland & 122516 & $\mathrm{D}$ & 53.60 & 8.68 \\
\hline National Bank of Greece & ETE & Greece & 104798 & $\mathrm{D}$ & -186.01 & 25.86 \\
\hline Banco Comercial Portugues & $\mathrm{BCP}$ & Portugal & 89744 & $\mathrm{D}$ & 25.95 & 5.92 \\
\hline Banco Espirito Santo & BES & Portugal & 83690 & - & 37.05 & 7.37 \\
\hline Wustenrot \& Wurttembergische & WUW & Germany & 77192 & - & -4.68 & 1.89 \\
\hline Mediobanca & MB & Italy & 72841 & - & 29.96 & 5.55 \\
\hline Piraeus Bank & TPEIR & Greece & 70406 & $\mathrm{D}$ & -146.26 & 21.33 \\
\hline Eurobank Ergasias & EUROB & Greece & 67653 & $\mathrm{D}$ & -7.49 & 19.93 \\
\hline Banca popolare Emilia Romagna & $\mathrm{BPE}$ & Italy & 61637 & - & 30.46 & 5.77 \\
\hline Alpha Bank & ALPHA & Greece & 58357 & $\mathrm{D}$ & -121.81 & 18.04 \\
\hline Bankinter & $\mathrm{BKT}$ & Spain & 58165 & - & 83.17 & 5.68 \\
\hline Banca Popolare di Milano & PMI & Italy & 52475 & - & 10.74 & 6.06 \\
\hline Banca Carige & CRG & Italy & 49325 & - & -18.23 & 7.07 \\
\hline Aareal Bank & ARL & Germany & 45734 & - & 37.33 & 4.34 \\
\hline Pohjola Bank Oyj & POH1S & Finland & 44623 & - & 14.87 & 3.38 \\
\hline Banco BPI & BPI & Portugal & 44564 & $\mathrm{D}$ & 22.54 & 6.02 \\
\hline Bank of Cyprus & $\mathrm{CPB}$ & Cyprus & 33762 & - & -60.01 & 10.77 \\
\hline IKB Deutsche Industriebank & IKB & Germany & 31593 & - & 59.85 & 8.36 \\
\hline Banca Popolare di Sondrio & BPSO & Italy & 32349 & - & -3.35 & 3.74 \\
\hline Credito Emiliano & $\mathrm{CE}$ & Italy & 30748 & - & 30.57 & 4.50 \\
\hline Credito Valtellinese & CVAL & Italy & 29896 & - & -11.50 & 5.68 \\
\hline
\end{tabular}

G : Global Systemically Important Bank, D : Domestically Important Bank, T.Asset: Total Assets, YOY: Year on Year Returns, Stdev: standard deviations

and underrepresented in terms of German banks (has about $20 \%$ of them). The above bias is the result of the structure of the banking systems in the 
different countries, and especially of medium sized banks, that typically operate at a local (subnational) level: while most such banks, in Italy (and in Greece), are listed, in Germany this is rarely the case, with other countries lying in between.

The market and financial data that we have considered has been obtained from Bankscope, a comprehensive database for individual banks across the world provided by the private company Bureau Van Dijk. In particular, the information that we use covers a year of price stock data, just before the start of the ECB supervision, with observations on a weekly basis. Precisely, our observation period goes from October 22, 2012, to October 18, 2013. From the Bankscope database, we have extracted the weekly closing stock prices for each bank, $P_{t}$ and, then, transformed them into weekly returns, defined as: $R_{t}=\log \left(P_{t} / P_{t-1}\right)$, where $t$ is a week in the last year and $t-1$ the week that precedes it.

Convergence Diagnostics. As discussed in the previous section, we choose $\tau=1$ as a threshold value for the Bayes factor. We run 2200 Gibbs iterations with 200 as burn-in. Our MCMC simulations are implemented in Matlab. We have verified posterior convergence of the algorithm by diagnosing the complexity of the network. For each sampled network, we have computed the Bayesian Information Criterion:

$$
\operatorname{BIC}(G)=-2 \log (P(\mathcal{X} \mid G))+m \log (T)
$$

where $P(\mathcal{X} \mid G)$ is the marginal likelihood, $m$ is the number of edges in the graph $(G)$ and $T$ is the number of observations. We have then monitored convergence using potential scale reduction factor (PSRF) of [22]. The approach divides the sampled chains into three parts to compute within-chain and between-chain covariances to test whether all the chains converge to the same posterior distribution. The chain is said to have properly converged if $P S R F \leq 1.2$. The results from our convergence diagnostics, shown in Figure 1 indicates that all our simulations converged with a PSRF smaller than 1.02 .

Results. We now present the results from the application of Bayesian graphical models to the weekly log returns of the 45 considered banks. We applied to such data both a (non-hierarchical) Bayesian graphical model, and our proposed Bayesian hierarchical models that enlarges the state space of each bank log return variables with country specific log return variables, obtained averaging the returns of the banks in each country. This inclusion, if significant, is expected to lower the connections between banks, and espe- 


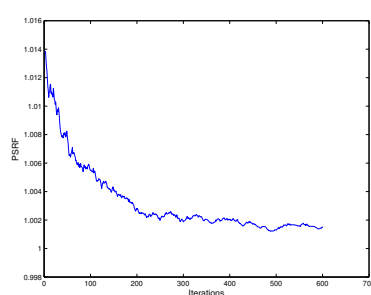

(a) Non-HN

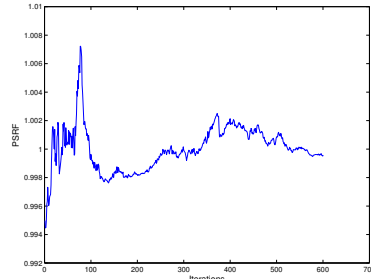

(b) HN (Countries)

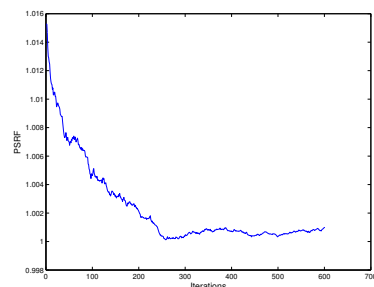

(c) HN (Banks)

FIGURE 1. Evolution of the Potential Scale Reduction Factor (PSRF) for convergence diagnostics of the networks: (1a) Non-Hierarchical Network; (1b): Hierarchical Network (between Countries); (1c): Hierarchical Network (between Banks).

cially cross-border ones, as connections between banks may be replaced by connections between countries.

Figure 2a shows the unconditional graphical network model between banks with the highest a posteriori probability, in the non hierarchical model, and Figure $2 \mathrm{~b}$ the same best model, conditional on the country to country relationships, in the hierarchical model.

From Figure 2a note that the model is highly interconnected, and it is rather difficult to interpret. The only apparent message conveyed is about banks that appear "peripheral", with a lower degree and a lower centrality measures. Such banks range from the troubled Greek banks Alpha bank and Piraeus Bank, and Dexia bank, to medium size banks such as Wustenrot and Wurttenbergische in Germany, Pohjola Bank in Finland, UBI in Italy, and two internationally oriented SIFIs such as Banco de Bilbao and BNP. These banks, because of their lower centrality, seem to appear less contagious/subject to contagion.

Figure 2b, instead presents a much clearer picture: the total number of links drop from 711 to 95 . There is a remarkable difference between the unconditional results in Figure 2a and those obtained conditionally on a country effect, in Figure 2b. The most evident difference is the lower degree of connectivity between banks, especially at the cross-border level.

This means that the country effect explains a lot of the co-movements between the returns of the banks. Table 3, that contains, for each bank, the centrality measure and the total number of connections, gives further evidence in this direction: indeed, most banks have connections mainly with banks of their country, and this is a further confirmation of the fact that share prices of banks heavily depend on the risk of the countries in which they operate. This also explains why the most central and connected banks 


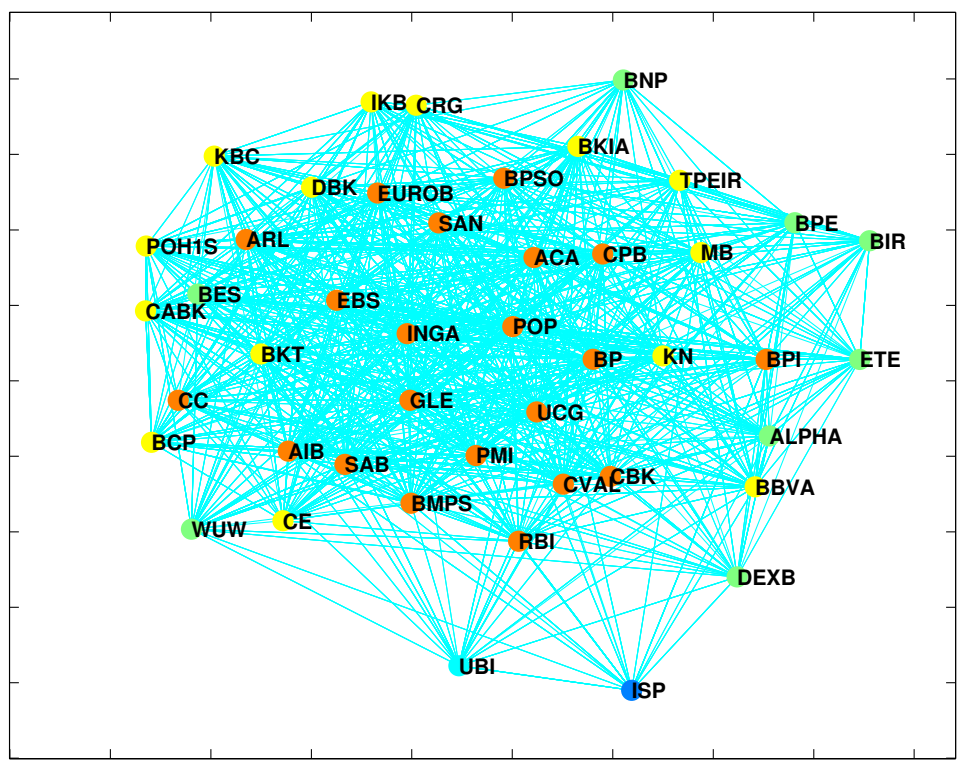

(a) Non-Hierarchical Network (Total Links : 711)

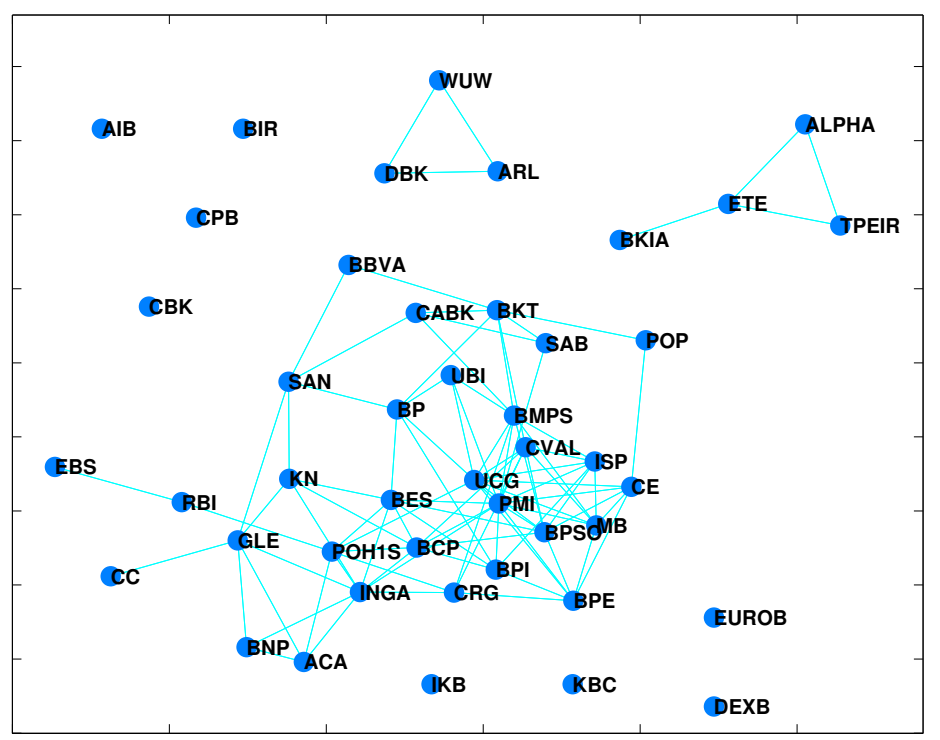

(b) Hierarchical Network (Total Links : 95)

FiguRE 2. Comparison of Inter-Bank connections from: (2a): a Non-Hierarchical Network and (2b): a Hierarchical Network. Banks are represented using their Bank Codes (See Table 1 for Bank Names). 
in Table 3 are Italian banks, which are more represented in the sample. To the other side of the spectrum, German banks, that appear disconnected from other countries' banks. Similarly, Greek banks form their own circle of troubled banks, together with the Spanish Bankia.

Besides the existence of a country effect, Table 3 emphasizes that some Systematically Important Financial Institutions (SIFI in Table 1) are potentially more contagious than others, as they are more connected. This is the case of Unicredit, heavily linked to most italian banks; of ING, strongly interconnected at an international level; and, although to a lesser extent, for the French banks BPCE, Credit Agricole and Societe General and the Spanish Banco Santander. Other SIFIs, including the two German ones Deutsche bank and Commerzbank, as well as BNP Paribas, are less central.

We now examine in detail the inter country linkages estimated by the hierarchical model. Figure 3 shows the between country graphical network that is learned (model averaged) from the data, and Table 2 gives the corresponding centrality measures. To aid interpretation, we have added a marker for the estimated sign of the partial correlation found: positive or negative.

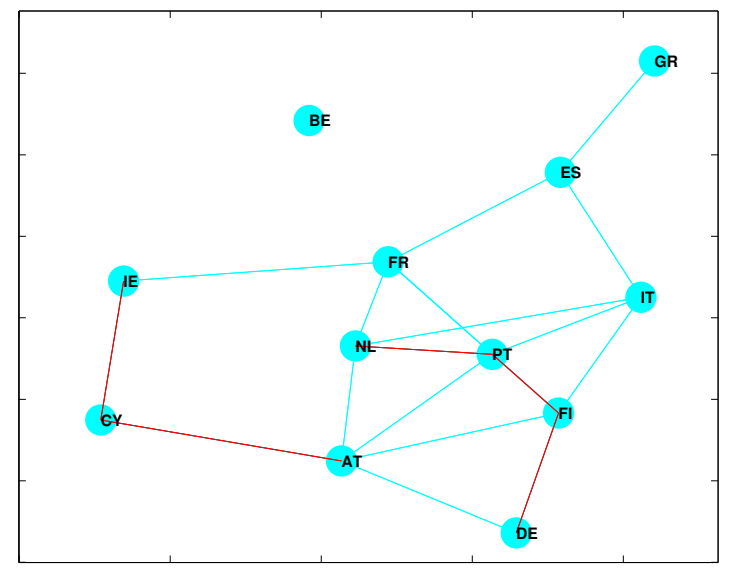

FIGURE 3. Inter-Country connections from the Hierarchical Network (Total Links : 19). AT stands for Austria, BE for Belgium, CY for Cyprus, DE for Germany, ES for Spain, $F I$ for Finland, FR for France, GR for Greece, IE for Ireland, IT for Italy, NL for the Netherlands and PT for Portugal. The color of links indicate the signs of the partial correlations: red for negative and blue for positive.

From Figure 3 and Table 2, notice that country financial systems are not much connected, confirming the image of Europe as a "market with financial frictions". 
TABLE 2

Inter-Country centrality measures

\begin{tabular}{clllccrr}
\hline Rank & Code & Country & Eig.V & Degree & Num. Banks & YOY & Stdev \\
\hline 1 & PT & Portugal & 0.4497 & 5 & 5 & 5.24 & 4.64 \\
2 & FI & Finland & 0.4148 & 5 & 1 & 24.34 & 4.52 \\
3 & AT & Austria & 0.3714 & 5 & 7 & 15.45 & 3.80 \\
4 & FR & France & 0.3695 & 5 & 3 & 11.21 & 6.68 \\
5 & NL & Netherland & 0.3692 & 4 & 12 & 59.85 & 8.36 \\
6 & IT & Italy & 0.3412 & 4 & 1 & -10.39 & 9.49 \\
7 & DE & Germany & 0.1895 & 2 & 5 & 16.04 & 4.92 \\
8 & ES & Spain & 0.1818 & 3 & 2 & -61.51 & 10.98 \\
9 & CY & Cyprus & 0.1178 & 2 & 1 & 44.17 & 4.96 \\
10 & IE & Ireland & 0.1174 & 2 & 2 & 16.18 & 4.63 \\
11 & GR & Greece & 0.0438 & 1 & 4 & -24.67 & 11.65 \\
12 & BE & Belgium & 0 & 0 & 2 & 24.16 & 4.00 \\
\hline
\end{tabular}

In particular, due to the still persisting strong crisis, that generates high credit loss impairments, southern European countries, such as Greece, Spain and Italy are connected with each other. Similarly, so are stronger economies such as Germany, Austria and Finland. France act as gates between troubled southern countries and stronger ones, along with the Netherlands and Portugal whose banks have a high international exposure. Finally, Belgium, Ireland and Cyprus, smaller economies, follow very specific paths: Belgium, disconnected, because of the very different behaviour of its two banks: Dexia, under restructuring, and KBC, healthier; Cyprus, that went through a dramatic financial crisis, in the last year; Ireland, whose banks have gone through a year of gains, that followed years of crisis.

Indeed, looking at Table 2, the most contagious countries seem France, Portugal, Finland, Austria and Netherlands. While the French economy is indeed a gate between southern and Northern european economies, the other centralities can be explained by the multinational activities of the banks of the related countries.

Having estimated the country-to-country connections, we now look in detail the interdependencies between banks, that emerge from Figure $2 \mathrm{~b}$. As already remarked, Table 3 gives the corresponding numeric description. In particular, it gives, for each bank, its eigenvalue centrality measure, and the total number of links in the conditional model. Such total number is split between the within country links and the cross-border links of each bank.

We first focus on the within country links that are estimated by the Bayesian model averaged hierarchical graphical model. Figure 4 extracts from Figure $2 \mathrm{~b}$ the bank relationships that are learned from the data, within each country.

A first remark is that, conditionally on the country-to country relation- 


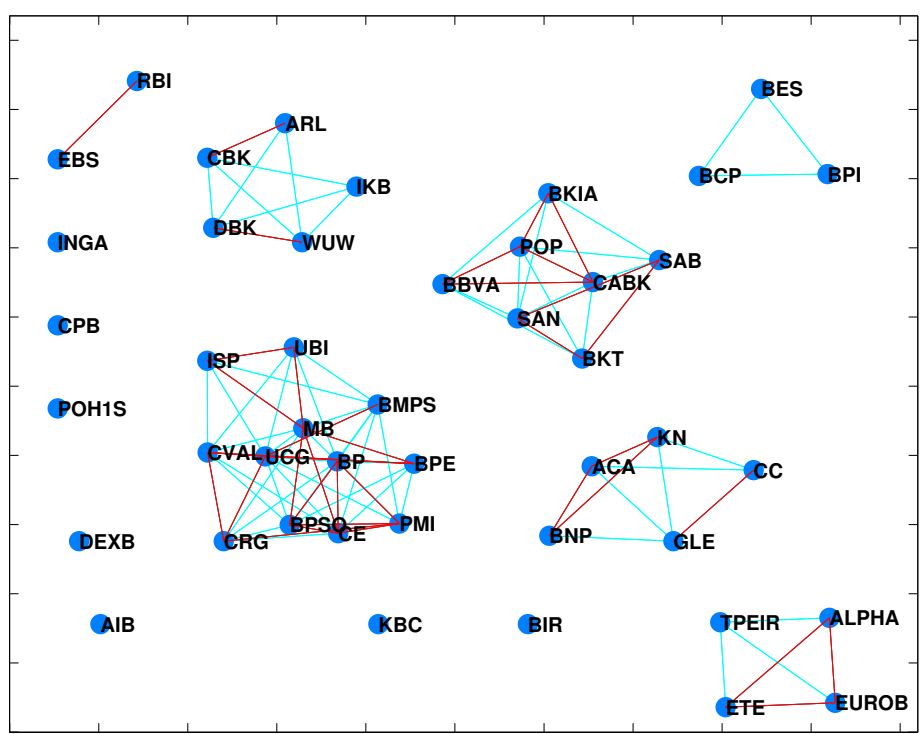

(a) Non-Hierarchical Network (Total Links : 96)

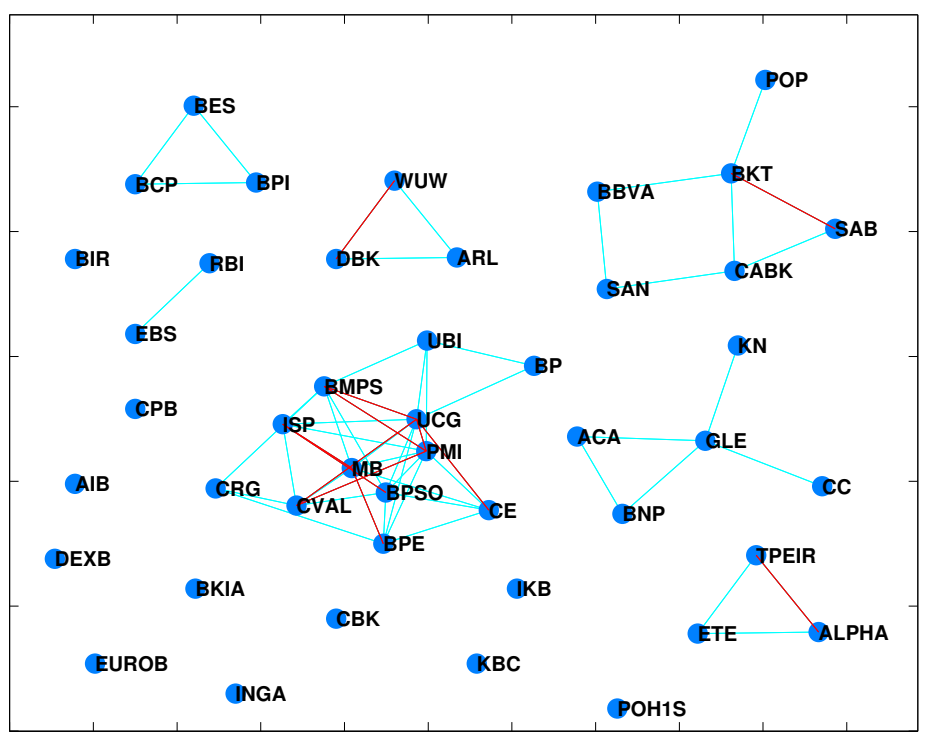

(b) Hierarchical Network (Total Links : 58)

FiguRE 4. Comparison of Within-Country connections from (4a): a non-Hierarchical Network and (4b): a Hierarchical Network. Banks are represented using their Bank Codes (See Table 1 for Bank Names). The color of links indicate the signs of the partial correlations: red for negative and blue for positive. 
HIERARCHICAL FINANCIAL GRAPHICAL MODELS

TABLE 3

Inter-Bank centrality measures from the Hierarchical Network

\begin{tabular}{|c|c|c|c|c|c|c|c|}
\hline & \multirow[t]{2}{*}{ Code } & \multirow[t]{2}{*}{ Bank Name } & \multirow[t]{2}{*}{ Country } & \multirow[t]{2}{*}{ Eig. V } & \multicolumn{3}{|c|}{ Degree } \\
\hline & & & & & Tot & W-C & $\mathrm{A}-\mathrm{C}$ \\
\hline 1 & PMI & Banca Popolare di Milano & Italy & 0.3995 & 14 & 9 & 5 \\
\hline 2 & UCG & UniCredit & Italy & 0.3314 & 11 & 10 & 1 \\
\hline 3 & BPSO & Banca Popolare di Sondrio & Italy & 0.3052 & 9 & 7 & 2 \\
\hline 4 & CVAL & Credito Valtellinese & Italy & 0.2587 & 8 & 6 & 2 \\
\hline 5 & BMPS & Banca Monte dei Paschi di Siena & Italy & 0.2557 & 9 & 7 & 2 \\
\hline 6 & ISP & Intesa Sanpaolo & Italy & 0.2552 & 7 & 6 & 1 \\
\hline 7 & MB & Mediobanca & Italy & 0.2482 & 7 & 7 & 0 \\
\hline 8 & $\mathrm{BPE}$ & Banca popolare Emilia Romagna & Italy & 0.2324 & 7 & 6 & 1 \\
\hline 9 & $\mathrm{BCP}$ & Banco Comercial Portugues & Portugal & 0.2289 & 8 & 2 & 6 \\
\hline 10 & BES & Banco Espirito Santo & Portugal & 0.2145 & 8 & 2 & 6 \\
\hline 11 & $\mathrm{CE}$ & Credito Emiliano & Italy & 0.1999 & 6 & 5 & 1 \\
\hline 12 & BPI & Banco BPI & Portugal & 0.1879 & 6 & 2 & 4 \\
\hline 13 & INGA & ING Groep & Netherland & 0.1751 & 9 & 0 & 9 \\
\hline 14 & POH1S & Pohjola Bank Oyj & Finland & 0.1490 & 7 & 0 & 7 \\
\hline 15 & UBI & Unione di Banche Italiane & Italy & 0.1437 & 4 & 4 & 0 \\
\hline 16 & CRG & Banca Carige & Italy & 0.1375 & 5 & 3 & 2 \\
\hline 17 & $\mathrm{BP}$ & Banco Popolare & Italy & 0.1325 & 6 & 2 & 4 \\
\hline 18 & $\mathrm{BKT}$ & Bankinter & Spain & 0.1081 & 7 & 4 & 3 \\
\hline 19 & $\mathrm{KN}$ & Natixis-BPCE Group & France & 0.0921 & 5 & 1 & 4 \\
\hline 20 & SAB & Banco de Sabadell & Spain & 0.0732 & 3 & 2 & 1 \\
\hline 21 & CABK & Caixabank & Spain & 0.0620 & 4 & 3 & 1 \\
\hline 22 & $\mathrm{ACA}$ & Credit Agricole & France & 0.0530 & 4 & 2 & 2 \\
\hline 23 & GLE & Societe Generale & France & 0.0525 & 6 & 4 & 2 \\
\hline 24 & SAN & Banco Santander & Spain & 0.0461 & 5 & 2 & 3 \\
\hline 25 & POP & Banco Popular Espanol & Spain & 0.0396 & 2 & 1 & 1 \\
\hline 26 & BNP & BNP Paribas & France & 0.0360 & 3 & 2 & 1 \\
\hline 27 & BBVA & Banco Bilbao Vizcaya Argentaria & Spain & 0.0198 & 2 & 2 & 0 \\
\hline 28 & RBI & Raiffeisen Bank International & Austria & 0.0195 & 2 & 1 & 1 \\
\hline 29 & $\mathrm{CC}$ & CIC Credit Mutuel Group & France & 0.0067 & 1 & 1 & 0 \\
\hline 30 & EBS & Erste Group Bank & Austria & 0.0025 & 1 & 1 & 0 \\
\hline 31 & $\mathrm{BIR}$ & Bank of Ireland & Ireland & 0 & 0 & 0 & 0 \\
\hline 32 & ALPHA & Alpha Bank & Greece & 0 & 2 & 2 & 0 \\
\hline 33 & EUROB & Eurobank Ergasias & Greece & 0 & 0 & 0 & 0 \\
\hline 34 & TPEIR & Piraeus Bank & Greece & 0 & 2 & 2 & 0 \\
\hline 35 & ETE & National Bank of Greece & Greece & 0 & 3 & 2 & 1 \\
\hline 36 & BKIA & Bankia & Spain & 0 & 1 & 0 & 1 \\
\hline 37 & DBK & Deutsche Bank & Germany & 0 & 2 & 2 & 0 \\
\hline 38 & CBK & Commerzbank & Germany & 0 & 0 & 0 & 0 \\
\hline 39 & DEXB & Dexia & Belgium & 0 & 0 & 0 & 0 \\
\hline 40 & $\mathrm{KBC}$ & KBC Group & Belgium & 0 & 0 & 0 & 0 \\
\hline 41 & $\mathrm{CPB}$ & Bank of Cyprus & Cyprus & 0 & 0 & 0 & 0 \\
\hline 42 & WUW & Wustenrot \& Wurttembergische & Germany & 0 & 2 & 2 & 0 \\
\hline 43 & ARL & Aareal Bank & Germany & 0 & 2 & 2 & 0 \\
\hline 44 & IKB & IKB Deutsche Industriebank & Germany & 0 & 0 & 0 & 0 \\
\hline 45 & AIB & Allied Irish Banks & Ireland & 0 & 0 & 0 & 0 \\
\hline
\end{tabular}

Tot : Total Degree $\quad$ W-C : Within Country Degree $\quad$ A-C : Across Country Degree

ships, the number of links between banks, within country, decreases from 96 to 58 . 
The results in Figure 4 can be read off jointly with the column of Table 3 that shows the Within Country links, country by country. We focus on the largest ones.

Italy. Italian banks seem to rotate around the two largest banks: Unicredit, and Intesa San Paolo, as well as with the investment bank Mediobanca, which has indeed governance relationships with both. Among the other banks the most central ones are the cooperative territorial banks such as Popolare di Milano, Banca Popolare di Sondrio, Credito Valtellinese and Banca Popolare Emilia Romagna, indeed linked with each other. Note that the two most troubled banks, Monte dei Paschi di Siena and Banca Carige, have different centrality: the former is more connected and, therefore, can spread its distress among more neighbours. We also underline that a remarkable aspect of the model is that it seems to be able to capture even regional (subnational) links between banks, expression of the fact that banks may share the same lenders and, therefore, similar risks. This is the case for: CVAL and BPSO, both operating mainly in the Lombardy region; BP and UBI, both operating in the north center-east region; BPE and CE both operating in the Emilia Romagna region.

Spain. In the case of Spain, the territorial banks Bankinter and Caixabank are the most central, within country. The two large banks Santander and Banco de Bilbao are less central, but related to each other. Finally, Bankia is disconnected from the others, due to its state led restructuring. Considerations on regional dependences can be drawn for spanish banks in a similar fashion to Italiian ones.

France. In France the Systematically Important Institution Societe Generale acts as a gate between the territorial bank groups BPCE and Credit Mutuel and the larger groups: BNP Paribas and Credit Agricole.

Germany. In Germany the Systematically Important Deutsche Bank is connected to both Aareal Bank and Wustenrot, while Commerzbank and IKB are isolated, with their respectively bad and good performances.

Greece. All Greek banks but Eurobank (involved in a restructuring plan) are related with each other, and this reflects the fact that they reflect a common deep financial crisis of the country.

From the above discussion, the existence of a country effect, that determines statistical correlations and dependencies between banks, is clear. From 
an economical viewpoint such effect can be explained as follows. On the asset side, banks acts as lenders and, thus, if the economy is doing badly, so do banks, as enterprises do not repay the given credit and/or go default. In addition, countries with high public debts typically persuade banks to buy the related government securities. When the economy is badly performing, the value of such bond decreases. On the liability side, depositors from troubled countries typically put less money in banks or withdraw it. Furthermore, when a bank does badly, the government may intervene, and capitalize it buying a relevant portion of shares. Because of this inter-linkage between banks and their countries, we expect stock prices of banks to be highly determined by a country risk effect, which may increase the interconnections between banks in troubled countries, siuch as southern European ones.

We now look at bank to bank connections, that are estimated by our model, across countries, rather than within each country. Figure 5 shows the across country between bank network that is learned from the data, extracted from $2 \mathrm{~b}$.

The results in Figure 5 can be read off jointly with the column of Table 3 that shows the Across Country links.

We remind the reader that, on the basis of the assumptions of the proposed hierarchical model, the less a country is connected, the less likely the presence of significant cross border relationships for its banks. To exemplify, a cross border correlation for a German (or an Irish) bank is less likely to remain in the model than a similar (in size) cross border correlation for a French (or a Portoguese) bank, as France (and Portugal) are much more central than Germany (and Belgium) in the country-to-country network.

From Figure 5, notice that the number of connections significantly decreases, from 615 to 37 , much more than what do the within country connections.

From Figure 5 and Table 3, the most connected banks, at the cross border level, are either banks in small countries, such as ING, Pohjola, Banco Commercial Portoguese and Banco Espirito Santo, or multinational SIFIs such as Unicredit and Societe Generale. Notice also the high centrality of territorial banks such as Banca Popolare di Milano, Banco Popolare, Banco BPI and BPCE, presumably as they have relevant portions of shares in the hand of international investment funds, that look at them with common portfolio based strategies.

Another interesting remark that can be drawn from Figure 5 concerns the banks with no cross-border connections: the Greek and the German banks, whose country, as already seen, is disconnected from the others; the Irish banks which have no specific connections beyond the aggregate country ones 


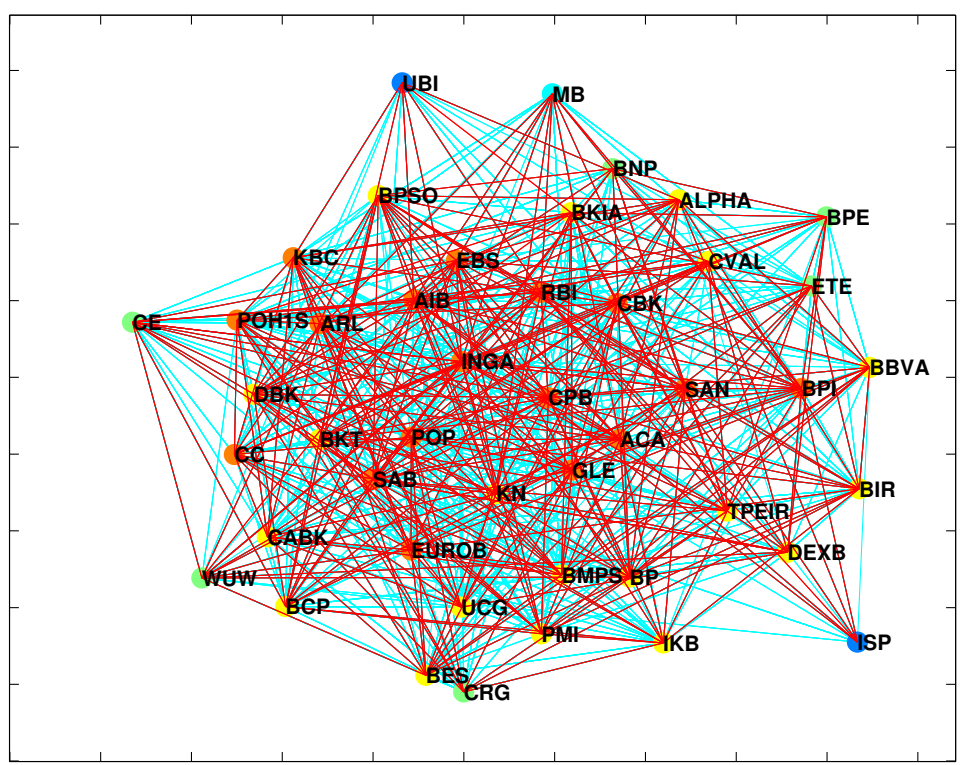

(a) Non-Hierarchical Network (Total Links : 615)

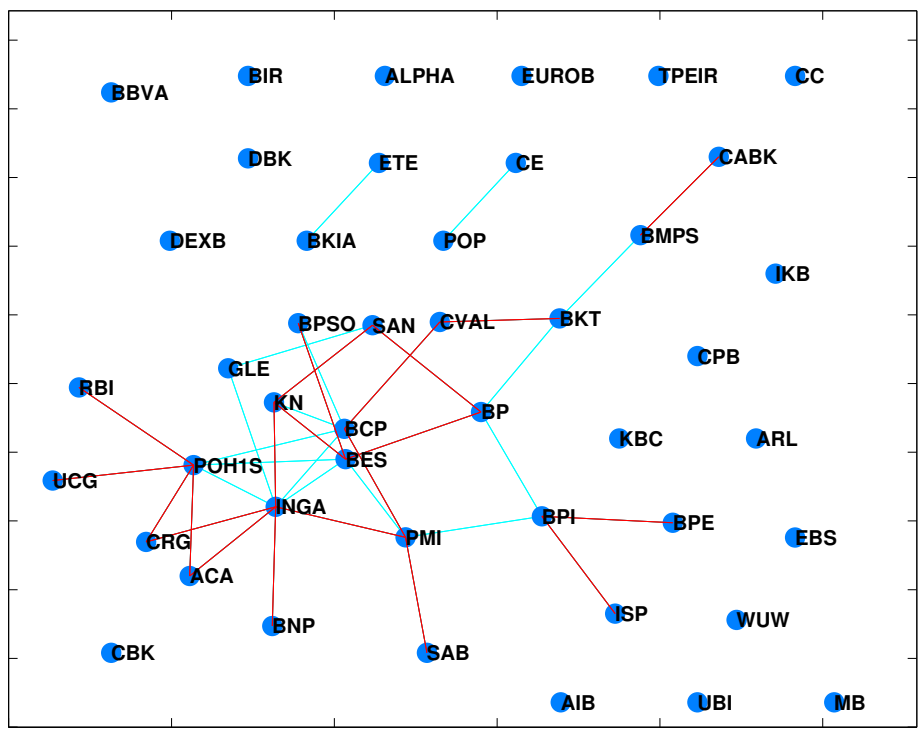

(b) Hierarchical Network (Total Links : 37)

Figure 5. Comparison of Inter-Bank connections across Countries from (5a): a NonHierarchical Network and (5b): a Hierarchical Network. Banks are represented using their Bank Codes (See Table 1 for Bank Names). The color of links indicate the signs of the partial correlations: red for negative and blue for positive. 
and, finally, the Bank of Cyprus, Bankia and the Belgian banks.

A final remark concerns the comparison between SIFIs, whose contagion is the most dangerous beacuse of their asset size. The most central ones appear Unicredit, ING, and the French banks Societe Generale, BPCE and Credit Agricole. Banco Santander, BNP Paribas and Banco Bilbao are connected, but less then the previous ones; Commerzbank, Dexia, and Deutsche Bank are the least connected.

Sensitivity Analysis. For sensitivity analysis purposes, we have run our computational algorithm with different log Bayes factor thresholds, $\tau=0$ and $\tau=2$. Table 4 shows the result of the total links of both hierarchical and non-hierarchical networks for the different Bayes factor thresholds.

Our results, summarised in Table 4 show that the results do not differ considerably from previous ones but the corresponding networks are, respectively, less or more interconnected. For example, in terms of the between country network, the estimated present links drop from 19 to 12 for $\tau=0$, and increase to 46 for $\tau=2$. In terms of specific relationships, we remark that the subtsance of what we found and discussed for the threshold of $\tau=1$, chosen according to what presented in the Simulation section, remains stable with other choices of the threshold.

TABLE 4

Sensitivity Analysis with different log Bayes factor thresholds

\begin{tabular}{clccc}
\hline \multirow{2}{*}{ Type } & \multicolumn{1}{c}{ Network } & \multicolumn{2}{c}{ Baye's Factor Threshold and Total Links } \\
& & $\tau=0$ & $\tau=1$ & $\tau=2$ \\
\hline \multirow{3}{*}{ Non-Hierarchical } & Over-all Inter Banks & 611 & 711 & 867 \\
& Within-Country & 85 & 96 & 106 \\
& Inter-Bank Across Country & 526 & 615 & 761 \\
& SIFI & 44 & 45 & 51 \\
\hline \multirow{2}{*}{ Hierarchical } & Over-all Inter Banks & 59 & 95 & 343 \\
& Within-Country & 41 & 58 & 93 \\
& Inter-Bank Across Country & 18 & 37 & 250 \\
& SIFI & 8 & 11 & 28 \\
& Inter-Countries & 12 & 19 & 46 \\
\hline
\end{tabular}

5. Conclusions. Financial network models are a useful tool to model interconnectedness and systemic risks in financial systems. Such models are essentially descriptive, and based on highly correlated networks.

The motivation of this paper is to provide a stochastic framework for financial network models, aimed at a more parsimonious and more realistic representation.

The paper contains two main research contributions in this direction. First 
we have introduces Bayesian Gaussian graphical models in the filed of systemic risk modelling, thus estimating the adjacency matrix of a network in a robust and coherent way. Second, we have proposed a hierarchical Bayesian graphical model that can usefully decompose dependencies between financial institutions into correlations into between countries and correlations between institutions, within and/or across countries.

We have applied our proposed methods to the largest Eurozone banks, with the aim of identifying central institutions, more subject to contagion of or, conversely, whose failure could result in further distress or breakdowns in the whole system.

Our results show that, in the transmission of the perceived default risk, there is a strong country effect, that reflects the weakness and the strenth of the underlying economies. Besides the country effect, the most centsl banks appear the most international ones, especially if from a relatively small country.

Future applied research may include the extension of the model to different types of hierarchies of financial institutions (e.g. listed vs unlisted; private or public) and of countries (in a larger worldwide perspective).

These extension require the development of a Bayesian graphical model able to model different types of data signals: besides price shares, balance sheet data, analysts opinions and other sources of "soft" information.

More generally, the field of financial systemic risk modeling is an area where good statistical thinking and statistical analysis can contribute substantially to reach conclusions that are more and more important and timely for policy makers, both at the national and international levels.

\section{References.}

[1] Acharya, V. V., Pedersen, L. H., Philippon, T. and Richardson, M. (2010). Measuring systemic risk Working Paper No. 1002, Federal Reserve Bank of Cleveland.

[2] Adrian, T. and Brunnermeier, M. K. (2010). CoVaR Staff Reports No. 348, Federal Reserve Bank of New York.

[3] Ahelegbey, D. F., Billio, M. and Casarin, R. (2012). Bayesian Graphical Models for Structural Vector Autoregressive Processes Working Paper No. 36, Department of Economics, University Ca'Foscari of Venice.

[4] Altman, E. I. (1968). Financial ratios, discriminant analysis and the prediction of corporate bankruptcy. The journal of finance 23 589-609.

[5] Arena, M. (2005). Bank failures and bank fundamentals: A comparative analysis of Latin America and East Asia during the nineties using bank-level data. Journal of Banking and Finance 32 299-310.

[6] Barigozzi, M. and Brownlees, C. (2013). Nets: Network Estimation for Time Series Working Paper.

[7] Bernardo, J. M., Berger, J. O., Dawid, A. P. and Smith, A. F. M. (1996). Bayesian Statistics 5. Oxford: Oxford University Press. 
[8] Billio, M., Getmansky, M., Lo, A. W. and Pelizzon, L. (2012). Econometric measures of connectedness and systemic risk in the finance and insurance sectors. Journal of Financial Economics 104535 - 559.

[9] Brownlees, C. T. and Engle, R. F. (2011). Volatility, Correlation and Tails for Systemic Risk Measurement Technical report, New York University.

[10] Brunnermeier, M. K. and Oenmke, M. (2012). Bubbles, Financial Crises, and Systemic Risk NBER Working Papers No. 18398, National Bureau of Economic Research, Inc.

[11] Casella, G. and Robert, C. P. (2004). Monte Carlo Statistical Methods. Springer Verlag, New York.

[12] Castrén, O. and Kavonius, I. K. (2009). Balance sheet interlinkages and macrofinancial risk analysis in the euro area Working Paper, European Central Bank.

[13] Chen, H., Cummins, J. D., Viswanathan, K. S. and Weiss, M. A. (2013). Systemic risk and the interconnectedness between banks and insurers: An econometric analysis. (forthcoming), Journal of Risk and Insurance.

[14] Chickering, D. M., Heckerman, D. and Meek, C. (2004). Large-Sample Learning of Bayesian Networks is NP-Hard. Journal of Machine Learning Research 5 12871330 .

[15] Cole, R. A. and Gunther, J. W. (1998). Predicting bank failures: A comparison of on-and off-site monitoring systems. Journal of Financial Services Research 13 103-117.

[16] Cont, R., Moussa, A. and Santos, E. (2011). Network structure and systemic risk in banking systems. Edson Bastos e, Network Structure and Systemic Risk in Banking Systems (December 1, 2010).

[17] Davis, E. P. and KARIM, D. (2008). Comparing early warning systems for banking crises. Journal of Financial stability 4 89-120.

[18] Edwards, D. (1990). Hierarchical interaction models (with discussion). Journal of the Royal Statistical Society, Series B 52 3-20 and 51-72.

[19] Fantazzini, D. and Maggi, M. (2013). Computing Reliable Default Probabilities in Turbulent Times. In Forthcoming, Rethinking Valuation and Pricing Models 241-255.

[20] Furfine, C. H. (2003). Interbank Exposures: Quantifying the Risk of Contagion. Journal of Money, Credit and Banking 35 111-128.

[21] Gai, P. and Kapadia, S. (2009). A Network Model of Super-systemic Crises. Documentos de trabajo del Banco Central. Banco Central de Chile.

[22] Gelman, A. and Rubin, D. B. (1992). Inference from Iterative Simulation Using Multiple Sequences, (withdiscussion). In Statistical Science 7 457-511.

[23] Georg, C.-P. and Poschmann, J. (2010). Systemic risk in a network model of interbank markets with central bank activity. Jena Economic Research Papers 2010 $-033$.

[24] Giudici, P. and Castelo, R. (2001). Association models for web mining. Data mining and knowledge discovery 5183 - 196.

[25] Giudici, P. and Green, P. J. (1999). Decomposable graphical Gaussian model determination. Biometrika 86 785-801.

[26] Guo, J., Levina, E., Michailidis, G. and Zhu, J. (2011). Joint estimation of multiple graphical models. Biometrika 98 1-15.

[27] Guo, J., Levina, E., Michailidis, G. and ZHU, J. (2013). Estimating heterogeneous graphical models for discrete data with an application to roll call voting. Annals of Applied Statistics.

[28] Gup, B. E. (1998). Bank failures in the Major trading countries of the world: causes and estimation. Quorum Books. 
[29] Gyftodimos, E. and Flach, P. A. (2002). Hierarchical bayesian networks: A probabilistic reasoning model for structured domains. In Proceedings of the ICML-2002 Workshop on Development of Representations. University of New South Wales 23-30.

[30] Halaj, G. (2013). Optimal asset structure of a bank - bank reactions to stressful market conditions Working Paper Series No. 1533, European Central Bank.

[31] Hensman, J., Lawrence, N. D. and Rattray, M. (2013). Hierarchical Bayesian modelling of gene expression time series across irregularly sampled replicates and clusters. BMC bioinformatics $141-12$.

[32] Huang, X., Zhou, H. and Zhu, H. (2011). Systemic risk contributions. In Macroprudential regulation and policy, (B. for International Settlements, ed.). BIS Papers chapters 60 36-43. Bank for International Settlements.

[33] Idier, J., Lamé, G. and Mésonnier, J. S. (2013). How useful is the Marginal Expected Shortfall for the measurement of systemic exposure? A practical assessment Working papers No. 348, Banque de France.

[34] Kanno, M. (2013). Credit migration forecasting and correlation between business and credit cycles Technical report, Kanagawa University.

[35] Kass, R. E. and RAftery, A. E. (1995). Bayes factors. Journal of the american statistical association 90 773-795.

[36] Kenny, G., Kostka, T. and Masera, F. (2013). Can macroeconomists forecast risk? Event-based evidence from the euro area SPF Working Paper Series No. 1540, European Central Bank.

[37] KlOmp, J. and HaAn, J. D. (2012). Banking risk and regulation: Does one size fit all? Journal of Banking and Finance 36 3197-3212.

[38] Koopman, S. J., Lucas, A. and SchwaAB, B. (2011). Modeling frailty-correlated defaults using many macroeconomic covariates. Journal of Econometrics 162312 325.

[39] Lauritzen, S. L. (1996). Graphical models. Oxford University Press.

[40] Lauritzen, S. L. and Wermuth, N. (1989). Graphical models for associations between variables, some of which are quantitative and some qualitative. Annals of Statistics 17 31-57.

[41] De Lisa, R., Zedda, S., Vallascas, F., Campolongo, F. and Marchesi, M. (2011). Modelling Deposit Insurance Scheme Losses in a Basel 2 Framework. Journal of Financial Services Research 40 123-141.

[42] Liu, J. S. (1994). The Collapsed Gibbs Sampler in Bayesian Computations with Applications to a Gene Regulation Problem. Journal of the American Statistical Association 89958 - 966.

[43] Madigan, D. and York, J. (1995). Bayesian graphical models for discrete data. International Statistical Review 63 215-232.

[44] Madigan, D., York, J. and Allard, D. (1995). Bayesian Graphical Models for Discrete Data. International Statistical Review / Revue Internationale de Statistique $63215-232$.

[45] Mare, D. S. (2012). Contribution of macroeconomic factors to the prediction of small bank failures. Available at SSRN 2050029.

[46] Markose, S., Giansante, S., Gatkowski, M. and Shaghaghi, A. R. (2010). Too Interconnected To Fail: Financial Contagion and Systemic Risk in Network Model of CDS and Other Credit Enhancement Obligations of US Banks. Economics Discussion Papers 683 21-50.

[47] Merton, R. C. (1974). On the pricing of corporate debt: the risk sructure of interest rates. Journal of Finance $\mathbf{2} 449$ - 471.

[48] Nier, E., Yang, J., Yorulmazer, T. and Alentorn, A. (2007). Network models 
and financial stability. Journal of Economic Dynamics and Control 312033 - 2060.

[49] Basel Committee on Banking Supervision (2011). A global regulatory framework for more resilient banks and banking systems Technical Report, Bank for International Settlements.

[50] PEARL, J. (1988). Probabilistic reasoning in intelligent systems: networks of plausible inference. Morgan Kaufmann publishers, San Mateo, CA, USA,.

[51] Peltonen, T. A., Scheicher, M. and Vuillemey, G. (2013). The network structure of the CDS market and its determinants Working Paper Series No. 1583, European Central Bank.

[52] Resti, A. and Sironi, A. (2007). Risk management and shareholders' value in banking: from risk measurement models to capital allocation policies $\mathbf{4 1 7}$. Wiley.

[53] Roberts, G. O. and SAHu, S. K. (1997). Updating schemes, covariance structure, blocking and parametrisation for the Gibbs sampler. Journal of the Royal Statistical Society 59291 - 318.

[54] Rose, P. S. and Kolari, J. W. (1985). Early warning systems as a monitoring device for bank condition. Quarterly Journal of Business and Economics 2443 - 60.

[55] Roth, M. (1994). Too big to fail and the instability of the banking system: some insights from foreign countries. Business Economics 4 43-49.

[56] Segoviano, M. A. and Goodhart, C. A. (2009). Banking Stability Measures IMF Working Papers No. 09/4, International Monetary Fund.

[57] Sharpe, W. F. (1964). Capital Asset Prices: A theory of market equilibrium under conditions of risk. Journal of Finance 19 425-442.

[58] Sinkey, J. F. (1975). A multivariate statistical analysis of the characteristics of problem banks. The Journal of Finance 30 21-36.

[59] TAM, K. Y. and KIANG, M. Y. (1992). Managerial applications of neural networks: the case of bank failure predictions. Management Science 38 926-947.

[60] VAsiceK, O. A. (1984). Credit valuation Technical Report, KMV corporation.

[61] Vazquez, F. and Federico, P. (2012). Bank funding structures and risk: Evidence from the global financial crisis. Available at SSRN 1997439.

[62] WANG, H. and LI, S. Z. (2012). Efficient Gaussian graphical model determination under G-Wishart prior distributions. Electronic Journal of Statistics 6 168-198.

[63] Wermuth, N. and Lauritzen, S. L. (1990). On substantive research hypotheses, conditional independence graphs and graphical chain models (with discussion). Journal of the Royal Statistical Society, Series B 52 21-50.

[64] Whittaker, J. (1990). Graphical Models in Applied Multivariate Statistics. John Wiley, Chichester.

[65] Zhang, D., Wells, M. T., Turnbull, B. W., Sparrow, D. and Cassano, P. A. (2005). Hierarchical Graphical Models. Journal of the American Statistical Association 100 719-727. 